\title{
Congenital giant pigmented nevi: Clinical features and risk of malignancy
}

\author{
Michael J Weinberg BSc MSc MD, Mohammed M Al-Qattan MBBS FRCS, Ronald M \\ Zuker MD FRCSC FACS, Hugh G Thomson MD MS FRCSC FACS, William K Lindsay \\ MD BSc MS FRSCC \\ Division of Plastic Surgery, Hospital for Sick Children, and University of Toronto, \\ Toronto, Ontario
}

\begin{abstract}
MJ Weinberg, M Al-Qattan, RM Zuker, HG Thomson, WK Lindsay. Can J Plast Surg 1996;4(2):94-98.

There is general agreement that congenital giant pigmented nevi (CGPN) are precursors to malignant melanoma; however, the magnitude of the risk of malignant transformation is the subject of wide controversy. The goal of this study was to present the authors' experience with CGPN and more specifically their experience with the risk of malignancy. To identify the general features of CGPN a detailed retrospective chart review was performed at The Hospital for Sick Children in Toronto (1979 to 1994, $\mathrm{n}=84$ ). There were 39 boys and 45 girls. The average size at presentation was $5.24 \%$ of the body surface area, and $36.9 \%$ of the nevus were located on the head and neck. An important finding was the high percentage of associated extra cutaneous disorders in patients with CGPN (23\%) including a case of leptomeningeal melanocytosis. Tissue expansion was the most commonly used treatment modality. One case of malignant melanoma arising from CGPN was identified. To ensure that all cases of malignant melanoma were identified in this cohort, a questionnaire was sent to all plastic surgeons in Ontario $(n=118)$, and data from the Ontario Cancer Registry were reviewed using the diagnostic codes for malignant melanoma and for pigmented nevus. One case of malignant melanoma was identified in all records. Thus CGPN poses a significant management challenge to the plastic surgeon and the risk of malignancy is low.
\end{abstract}

Key Words: Congenital nevus, Giant hairy nevus, Malignant melanoma

\section{Naevi pigmentaires géants congénitaux: Caractéristiques cliniques et risque de cancer}

RÉSUMÉ : On s'entend en général sur le fait que les naevi pigmentaires géants congénitaux (NPGC) soient des précurseurs du mélanome malin; or, l'ampleur du risque d'une évolution maligne fait l'objet d'une importante controverse. Le but de cette étude était de présenter l'expérience des auteurs en matière de NPGC et plus précisément, leur expérience à mesurer le risque d'une évolution néoplasique. Pour identifier les caractéristiques générales des NPGC, un bilan rétrospectif sous forme de tableau détaillé a été dressé au Hospital for Sick Children de Toronto (1979 à 1994, n=84). Le groupe comprenait 39 garçons et 45 filles. La taille moyenne au moment de la première consultation était de 5,24\% de la surface corporelle, et 36,9\% des naevi se trouvaient dans la région de la tête et du cou. Une importante observation a été le fort pourcentage 
de troubles cutanés associés chez les patients présentant des NPGC ( $23 \%)$, y compris un cas de mélanocytose leptoméningée. L'expansion tissulaire a été la modalité thérapeutique la plus utilisée. Un seul cas de mélanome malin découlant d'un NPGC a été identifié. Pour s'assurer que tous les cas de mélanome malin soient identifiés dans cette cohorte, un questionnaire a été envoyé à tous les chirurgiens plasticiens de l'Ontario $(\mathrm{n}=118)$, et les données du Ontario Cancer Register ont été passées en revue à l'aide des codes diagnostiques concernant les mélanomes et les naevi pigmentaires. Un cas de mélanome malin a été identifié parmi tous les dossiers. Le NPGC représente donc un défi thérapeutique de taille aux chirurgiens plasticiens et le risque de néoplasie est bas.

While there is agreement that congenital giant pigmented nevi (CGPN) are precursors to malignant melanoma, the magnitude of the risk of malignant transformation is the subject of wide controversy. On reviewing the literature (1-15), the risk of malignancy varied from $0 \%$ to $42 \%$ (Table 1 ). This variability reflects the relative rarity of CGPN and that different studies have looked at different patient populations and different age groups. The two highest published incidences (30\% and $42 \%$, respectively) were reported by pathologists and these studies were based on consultations for highly suspicious lesions $(4,5)$. Therefore, it is believed that these pathology reviews represent an incidence higher than represented in the general population (16).

TABLE 1: Risk of malignant transformation of CGPN in different studies

$\begin{array}{lcc}\text { Author } & \begin{array}{c}\text { Incidence of malignant } \\ \text { transformation (\%)* }\end{array} & \text { Reference } \\ \text { Conway } & 10 & 1 \\ \text { Pers } & 2 & 2 \\ \text { Greeley et al } & 10.7 & 3 \\ \text { Reed et al } & 30 & 4 \\ \text { Bergfeld et al } & 42 & 5 \\ \text { Kaplan } & 14 & 6 \\ \text { Lanier et al } & 7.5 & 7 \\ \text { Lorentzen et al } & 2 & 8 \\ \text { Williams } & 0 & 9 \\ \text { Arons et al } & 0 & 10 \\ \text { Quaba et al } & 5.1 & 11 \\ \text { Kipikasa et al } & 2.3 & 12 \\ \text { Bauer et al } & 1.3 & 13 \\ \text { Ruiz-Maldonaldo et al } & 5 & 14 \\ \text { Casson et al } & 0 & 15\end{array}$

*Incidence of malignant transformation is the incidence during the observation period of the study and not the calculated lifetime risk of malignancy. CGPN Congenital giant pigmented nevi

Clinical studies may be criticized for their scientific methods, especially bias. For example, the study undertaken by Quaba and Wallace (11) in England and Wales was prompted by the tragic deaths of two children from metastatic malignant melanoma arising in CGPN who were under the care of one of the authors. Because of their strict inclusion criteria and the retrospective nature of their survey, Quaba and Wallace only included 39 cases of CGPN in their series and, hence, the risk of malignant 
transformation in that study was two of $39(5.1 \%)$ during a mean of nine years of observation. The high incidence of malignancy associated with CGPN in clinical studies may also be attributable to inappropriate initial diagnosis. For example, one of the patients reported by Greeley et al (3) had a Spitz nevus (17), a benign lesion. Other authors such as Kaplan (6) included melanomas arising in giant cellular blue nevi in their series. The cutaneous blue nevus $(18,19)$ is a complex entity and can behave as a benign, premalignant, locally malignant or malignant lesion and, thus, blue nevi should not be included in series of CGPN.

Prospective lifetime multicentre studies, following a large number of patients without intervention, could give an accurate estimate of the risk. Unfortunately, this is not clinically feasible. Lorentzen et al (8) retrieved reports from 151 patients with CGPN registered in the Danish Health System during a 60-year period and found three cases of malignant transformation. However, one of these three cases was a 28-year-old female with sarcoma arising in her CGPN. The patient's nevus had received very large doses of irradiation during childhood and it is likely that sarcoma developed because of the irradiation and not because of the nevus.

Leptomeningeal melanocytosis is a serious and frequently fatal condition that is known to be associated with benign CGPN of the craniofacial region $(4,20,21)$. It usually presents with hydrocephalus due to blockage of the cisternal pathways and obliteration of the arachnoid villi by the proliferating melanocytes. Malignant melanoma of the leptomeninges may also occur; however, this melanoma is a primary lesion of the central nervous system. Therefore, leptomeningeal melanocytosis should be considered as an associated lesion rather than a malignancy arising from cutaneous CGPN.

This particular study reports findings about CGPN in general and more specifically with respect to the risk of malignancy.

\section{MATERIALS AND METHODS}

The definition of 'giant' used for the head and neck area in this study was different than that used for the rest of the body. A 'giant' nevus of the head and neck was a lesion involving more than one half of $1 \%$ of the total body surface area. For the rest of the body, the nevus was considered 'giant' when it occupied greater than $1 \%$ of the total body surface area as measured by the patient's palm.

Three different methods were used to identify patients with melanoma arising in CGPN in Ontario: a questionaire distributed to all plastic surgeons practising in Ontario, a study of data from the Ontario Cancer Registry and a retrospective clinical review. The questionnaire was sent to all plastic surgeons $(\mathrm{n}=118)$ practising in Ontario. Specific questions were asked about the number of years in practice, the total number of CGPN seen and the number of melanomas arising in CGPN. The data from the Ontario Cancer Registry were reviewed from 1979 to 1992 (most recent data) using the diagnostic codes for malignant melanoma and for pigmented nevus. Pathology reports for all pediatric patients (birth to 19 years of age) with malignant melanoma were then studied for the presence of any pre-existing CGPN. In the retrospective clinical review the charts and photographs of 84 patients with CGPN seen at The Hospital for Sick Children in Toronto between 1979 and 1994 were reviewed. Clinical features, histopathology and treatment modalities were studied as well as the incidence of malignant transformation. 


\section{RESULTS}

\section{Questionnaire}

The response rate to the questionnaire was $41 \%$ (48 of 118). Plastic surgeons responding had an average of 12 years in practice. A total of 618 cases of CGPN were seen. Of these, three lesions developed malignant melanoma. After reviewing the clinical data and histopathology, two of the three cases were excluded. One case was a malignant cellular blue nevus of the scalp and the other case was a malignant melanoma arising in a congenital nevus of the upper limb, but the nevus measured only $5 \mathrm{~cm}$ in length and 1.5 $\mathrm{cm}$ in width. The third case was an eight-year-old boy who developed a malignant melanoma in a CGPN of the back and will be reported in detail in the retrospective clinical review.

\section{Ontario Cancer Registry}

During a 13-year period (1979 to 1992), the total number of malignant melanomas registered at the Ontario Cancer Registry was 13,540. Of these, 168 melanomas $(1.2 \%)$ were seen in the pediatric age group. A study of the pathology reports from the 168 cases identified only one case of melanoma in a CGPN. This case was the same 8-year-old boy identified from the questionnaire.

\section{Retrospective clinical review}

The charts and photographs of 84 pediatric patients with CGPN seen at The Hospital for Sick Children were reviewed. The group consisted of 45 females and 39 males and the average nevus size at presentation was $5.2 \%$ of the total body surface area. Only one patient had a family history of CGPN. The anatomical distribution of the CGPN is shown in Table 2. The most frequent site involved was the head and neck area (36.9\%). Most of the CGPN were brown $(70.2 \%)$, some were black $(17.9 \%)$ and others were mottled $(11.9 \%)$. The vast majority of CGPN were hairy $(82.1 \%)$ and about one third of cases (37\%) had multiple satellite nevi.

TABLE 2: Anatomical distribution of CGPN in 84 patients at The Hospital for Sick Children

Location

Head and

neck

Trunk

Extremity

Multiple sites

CGPN Congenital giant pigmented nevi
Number of patients (\%)

$31(36.9 \%)$

$22(26.2 \%)$

$20(23.8 \%)$

$11(13.1 \%)$ 
TABLE 3: Extra cutaneous disorders in 19 patients with CGPN seen at The Hospital for Sick Children

\begin{tabular}{ll}
$\begin{array}{l}\text { System involved } \\
\text { Cardiovascular }\end{array}$ & \multicolumn{1}{c}{ Disorders $^{*}$} \\
Central nervous & $\begin{array}{l}\text { Pulmonary stenosis } \\
\text { leptomeningeal melanocytosis }\end{array}$ \\
Musculoskeletal & $\begin{array}{l}\text { Congenital hip dislocation }{ }^{\dagger} \text {, trigger finger, limb } \\
\text { hypertrophy }\end{array}$ \\
Endocrine & Juvenile diabetes, hirsuitism \\
Respiratory & Asthma \\
Genitourinary & Hydrocele \\
Gastrointestinal & Celiac disease, lactose intolerance \\
Psychiatric & Adjustment disorder \\
Miscellaneous & Multiple congenital anomalies ${ }^{\dagger}$, \\
benign breast cyst
\end{tabular}

Three patients had associated benign skin lesions that consisted of a skin tag, a neurofibroma and a hemangioma. Nineteen patients had associated extra cutaneous disorders (Table 3). A two-year-old girl with a CGPN involving a significant part of her forehead and multiple other smaller nevi had leptomeningeal melanocytosis. The forehead nevus was totally excised and histological examination of the specimen showed a benign compound nevus. Four months postoperatively, the child was readmitted with speech difficulties. A computed tomography scan documented hydrocephalus and a lumbar puncture confirmed the diagnosis of leptomeningeal melanocytosis. The child died one month later of disseminated disease. 

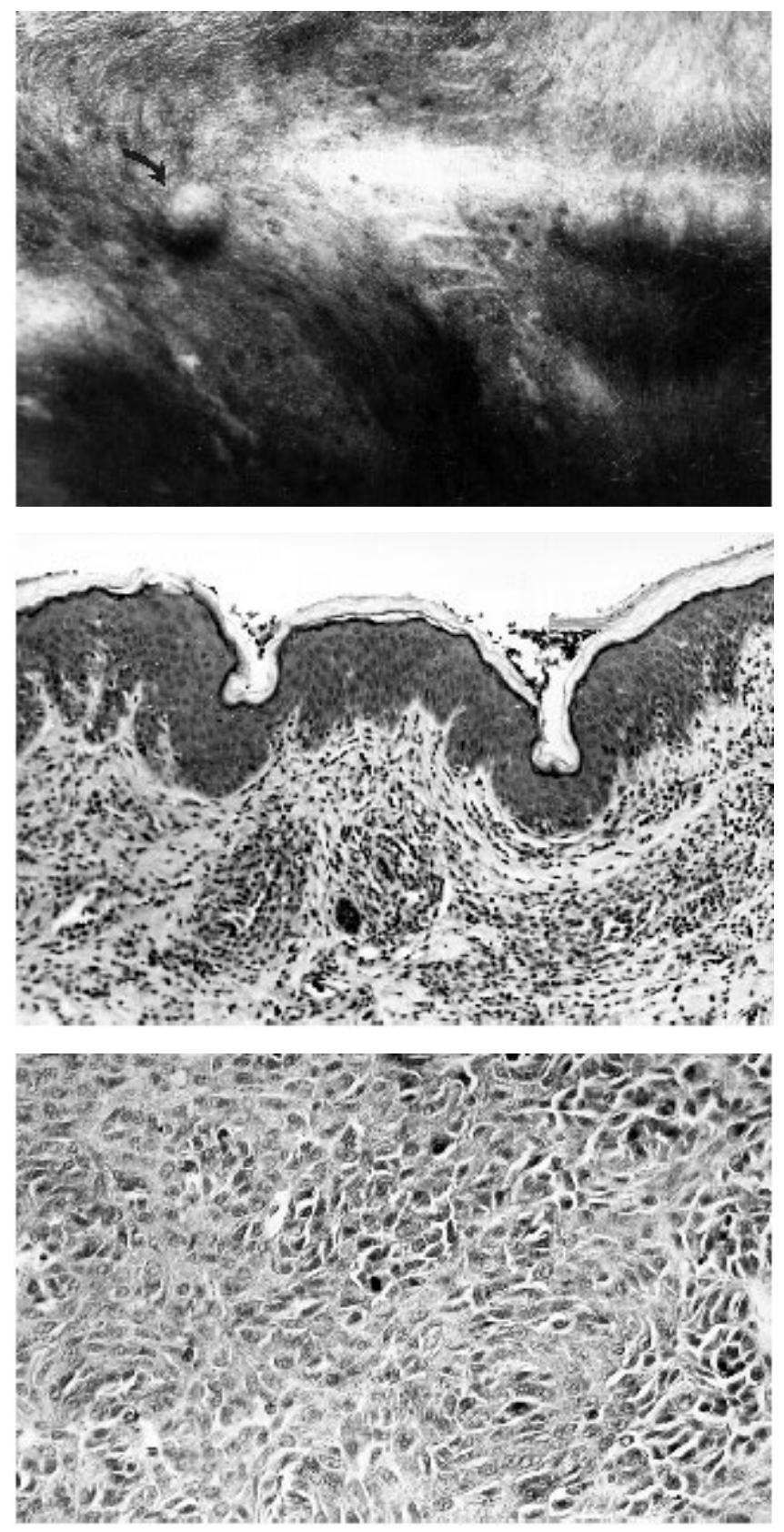

Figure 1) Top Close up of the nodule within a congenital giant pigmented nevus (CGPN) that was found to be malignant melanoma. Middle Close-up of skin showing dermal infiltrate of uniform small nevus cells typical of CGPN (hematoxylin and eosin $\times 65$ ). Bottom Close-up of solid part of malignant melanoma in deep dermis and subcutaneous tissue. Cells are large, form solid sheets and have hyperchromatic nuclei that show pleomorphism and mitotic activity 
Histologically, $71 \%$ of the lesions were compound nevi and $10 \%$ were intradermal nevi. The remaining $19 \%$ had no previous surgery and, hence, no biopsy was available. The primary treatment modality in patients is shown in Table 4. Tissue expansion was used most frequently in $41.6 \%$ of the patients. One patient who required multiple expansions suffered an anaphylactic reaction to latex while in the operating room. The group now uses latex-free products in all patients requiring multiple expansions.

One case of malignant melanoma was identified in this series in an eight-year-old boy with a CGPN covering $50 \%$ of his total body surface area. During infancy and early childhood, he had multiple excision and skin grafting procedures performed at another institution. He presented at eight years of age with a nodule on his back arising in the unexcised portion of his nevus (Figure 1). Excisional biopsy of the nodule revealed malignant melanoma. He subsequently underwent further resection with wide margins. The patient is now 19 years old with no evidence of recurrence or metastases.

\section{TABLE 4: Primary treatment modality in 84 patients with CGPN seen at The Hospital for} Sick Children

$\begin{array}{lc}\begin{array}{l}\text { Treatment } \\ \text { modality }\end{array} & \text { Number of patients (\%) } \\ \text { Observation: } \\ \begin{array}{l}\text { (a) awaiting } \\ \text { surgery } \\ \text { (b) only }\end{array} \\ \text { Skin grafting } & 11(14 \%) \\ \text { Tissue } & 4(5 \%) \\ \text { expansion } & 22(26 \%) \\ \text { Flap closure } & 35(42 \%) \\ \text { t pigmented nevi } & 12(14 \%)\end{array}$

\section{DISCUSSION}

The results of this study generally agree with other major series. Thomson (22) reviewed the literature and found that the definition of 'giant' was variable. Pers (2) defined 'giant' as palm size on the face and twice palm size elsewhere. Greeley et al (3) felt that an area larger than 144 square inches was 'giant', whereas Pilney et al (23) considered a lesion that could not be completely excised and closed primarily as 'giant'. Kopf et al (24) defined small lesions as less than $1.5 \mathrm{~cm}$ in diameter, median lesions as $1.5 \mathrm{~cm}$ to $19.9 \mathrm{~cm}$ and giant lesions as $20 \mathrm{~cm}$ or larger on the face and one palm size elsewhere.

An important finding of the retrospective clinical review was the high percentage of associated extra cutaneous disorders (19 of 84 or 23\%) including a case of leptomeningeal melanocytosis. Ruize-Maldonaldo et al (14) documented abnormalities of the electroencephalograms in $20 \%$ of the patients with CGPN involving the head and noted that nevi extensively involving the extremities resulted in reduced growth of the affected limb. In this patient population, electroencephalograms were not routinely done for CGPN of the head and impaired growth of the involved limbs was not seen. 
TABLE 5: Percentage of melanomas arising from CGPN in series of childhood melanomas

$\begin{array}{lccc}\text { Author } & \text { Total childhood melanomas* } & \begin{array}{c}\text { Number (\%) } \\ \text { melanomas arising from } \\ \text { CGPN }\end{array} & \text { Reference } \\ \text { Temple et al } & 21 & 0(0 \%) & 25 \\ \text { Lerman et al } & 12 & 2(16.7 \%) & 26 \\ \text { Stromberg } & 6 & 1(16.7 \%) & 27 \\ \text { Partoft et al } & 9 & 2(22 \%) & 28 \\ \text { Total } & 48 & 5(10.4 \%) & \end{array}$

${ }^{*}$ All cases and histological slides were re-examined by the authors to confirm the diagnosis of malignant melanoma. CGPN Congenital giant pigmented nevi

It is well established that the highest risk of malignancy in CGPN occurs during the first 20 years of life (16). Childhood melanomas are very rare and cancer registries may not reflect the true incidence of childhood melanomas because of frequent overdiagnosis. This overdiagnosis is mainly because of difficulties with differentiating Spitz nevus from invasive melanoma (25). It has been stated that one third of childhood melanoma arise from CGPN (11). This study, as well as other studies in the literature (25-28), did not confirm this statement (Table 5). Using questionnaires, Ontario Cancer Registry data and a retrospective clinical review, only a single case of malignant melanoma arising from CGPN was identified during the past 15 years in Ontario, indicating the rarity of this condition. The actual lifetime risk of malignant transformation is hard to calculate from these data because patients were of different age groups and were followed for various periods of time. It is possible that an early aggressive approach to these lesions is responsible for this low risk of malignant melanoma. In other words, surgical excision results in the debulking of tissue at risk for the development of malignant melanoma. Thus, we are strong proponents of early and complete removal of these lesions when clinically feasible.

Several treatment modalities have been used in the management of CGPN. Dermabrasion (29) or curettage (30) in the first few weeks of life were recommended because most nevus cells were noticed to lie in the superficial dermis soon after birth. However, Zitelli et al (31) showed that the number of nevus cells in the deep dermis is significant in early infancy and, hence, dermabrasion should not be considered as an effective treatment for the prevention of melanoma. The authors discourage lasers as a treatment modality for the reasons mentioned above.

Chemical peel has been used for nonsurgical candidates with giant nevi occupying most of the total body surface area. Peeling with phenol, although more toxic, was more effective than trichloracetic acid in depigmenting nevi (14). Peeling is not an accepted technique to treat CGPN because it does not remove the deep nevus cells and because of potential cardiac and renal toxic effects, as well as the frequent occurrence of scarring and bacterial infection in treated cases (14). The use of cultured epithelial autografts after excision of CGPN has been described, but the take of cultured epithelium is only $68 \%$ in the best hands (32).

Serial excision, tissue expansion and skin grafting $(13,22,23,33,34)$ remain the most frequently used methods to treat CGPN. However, in any treatment program, there must be awareness of the nonepidermal origin of malignant melanoma in CGPN as 
reported by Rhodes et al (35). Despite skin excision in these cases, melanoma develops from the residual nevus cells in the muscle fascia and even within the muscle.

The philosophy behind the treatment of CGPN is strongly influenced by the surgeon's experience with intralesional melanomas. For example, the tragic deaths of two children under the care of Wallace $(11,36)$ made him recommend early total prophylactic excision for all patients with CGPN (11). The experience of Rhodes et al (35) with nonepidermal origin of melanoma in CGPN made them recommend excision of CGPN at least to muscle fascia and even deeper excision in selected cases (37). On the other hand, treatment in institutions where patients have not died from intralesional melanoma emphasizes aesthetic considerations and malignant potential becomes a secondary concern $(9,22)$. Thus CGPN form a spectrum of lesions in terms of their extent, impact on patients lives and treatment challenges. The risk of malignancy in this series was $1 \%$.

ACKNOWLEDGEMENTS: We thank Dr J Phillips of the Department of Pathology at The Hospital for Sick Children for his help in the preparation of this manuscript.

\section{REFERENCES}

1. Conway H. Bathing trunk nevus. Surgery 1939;6:585-97.

2. Pers M. Gigantic pigmented nevi. Indications for operative treatment. Ugeskr Laeger 1963;125:613-9.

3. Greeley PW, Middleton AG, Curtin JW. Incidence of malignancy in giant pigmented nevi. Plast Reconstr Surg 1965;36:26-37.

4. Reed WB, Becker SW Sr, Becker SW Jr, Nickel WR. Giant pigmented nevi, melanoma, and leptomeningeal melanocytosis:

a clinical and histopathological study. Arch Dermatol 1965;91:100-19.

5. Bergfeld W, Helwig WB. New York, Exhibit at the Academy of Dermatology, December 1972.

6. Kaplan EN. The risk of malignancy in large congenital nevi. Plast Reconstr Surg 1974;53:421-8.

7. Lanier VC Jr, Pickrell KL, Georgiade NG. Congenital giant nevi: Clinical and pathological considerations. Plast Reconstr Surg 1976;58:48-54.

8. Lorentzen M, Pers M, Bretteville-Jensen G. The incidence of malignant transformation in giant pigmented nevi. Scand J Plast Reconstr Surg 1977;11:163-7.

9. Williams HB. Malignant melanomas in children. In: Williams HB, ed. Symposium on Vascular Malformations and Melanotic Lesions, vol 22. St Louis: CV Mosby, 1983:361. 10. Arons MS, Hurwitz S. Congenital nevocellular nevus: A review of the treatment controversy and a report of 46 cases. Plast Reconstr Surg 1983;72:355-65.

11. Quaba AA, Wallace AF. The incidence of malignant melanoma ( 0 to 15 years of age) arising in large congenital nevocellular nevi. Plast Reconstr Surg 1986;78:174-9.

12. Kipikasa A, Guzanin S, Urbanova E. Giant pigmented nevi from therapeutic aspects and their relationship to malignant degeneration. Plast Reconstr Surg 1988;81:1008. (Abst) 
13. Bauer BS, Vicari FA. An approach to excision of congenital giant pigmented nevi in infancy and early childhood. Plast Reconstr Surg 1988;82:1012-21.

14. Ruiz-Maldonaldo R, Tamayo L, Laterza AM, Duran C. Giant pigmented nevi:

Clinical, histopathologic and therapeutic considerations. J Pediatr 1992;120:1906-11.

15. Casson P, Colen S. Dysplastic and congenital nevi. Clin Plast Surg 1993;20:105-11.

16. Kaplan E, Nickoloff BJ. Clinical and histologic features of nevi

with emphasis on treatment approaches. Clin Plast Surg 1987;14:277-300.

17. Spitz S. Melanomas of childhood. Am J Pathol 1984;24:591-609.

18. Al-Qattan MM, Stranc MF, Anderson BJ. Cutaneous blue nevi:

Classification and malignant degeneration. Can J Plast Surg 1994;2:130-2.

19. Findler G, Hoffman HJ, Thomson HG, Becker L. Giant nevus of the scalp associated with intracranial pigmentation. J Neurosurg 1981;54:108-12.

20. Hoffman HJ, Freeman A. Primary malignant leptomeningeal melanoma in association with giant hairy nevi. Report of two cases. J Neurosurg 1967;67:62-71.

21. Williams HI. Primary malignant meningeal melanoma associated with benign hairy nevi. J Pathol 1969;99:171-3.

22. Thomson HG. Cutaneous melanocytic naevus. In: Mustarde JC, Jackson IT, eds.

Plastic Surgery in Infancy and Childhood. Edinburgh: Churchill Livingstone, 1988:673.

23. Pilney FT, Broadbent TR, Woolf RM. Giant pigmented nevi of the face: Surgical management. Plast Reconstr Surg 1967;40:469-74.

24. Kopf AW, Bart RS, Hennessay P. Congenital nevocytic nevi and malignant melanomas. J Am Acad Dermatol 1979;1:123-30.

25. Temple WJ, Mulloy RH, Alexander F, Marx LH, Jenkis M, Jerry LM. Childhood melanoma. J Pediatr Surg 1991;26:135-7.

26. Lerman RI, Murray D, O'Hara JM, Booher RJ, Foote FW Jr. Malignant melanomas of childhood. A clinicopathologic study and a report of 12 cases. Cancer 1970;25:436-49. 27. Stromberg BV. Malignant melanoma in children. J Pediatr Surg 1979;14:465-7.

28. Partoft S, Oserlind A, Hou-Jensen K, Drzewiecki KT. Malignant melanoma of the skin in children (0 to 14 years of age) in Denmark, 1943-1982. Scand J Plast Surg 1989;23:55-8.

29. Miller CJ, Becker DW Jr. Removing pigmentation by dermabrading naevi in infancy. Br J Plast Surg 1979;23:124-6.

30. Moss ALH. Congenital giant naevus: A preliminary report of a new surgical approach. Br J Plast Surg 1987;40:410-9.

31. Zitelli JA, Grant MG, Abell E, Boyd JB. Histologic patterns of congenital nevocytic nevi and implications for treatment. J Am Acad Dermatol 1984;11:402-9.

32. Gallico CG III, O'Connor NE, Compton CC, Remensnyder JP, Kehinde O, Green H. Cultured epithelial autografts for giant congenital nevi. Plast Reconstr Surg 1989;84:1-9. 33. Vergnes P, Taieb A, Malerille J, Larregne M, Bondonny JM.

Repeated skin expansion for excision of congenital giant nevi in infancy and childhood. Plast Reconstr Surg 1993;91:450-5.

34. Zuker RM, Iconomou TG, Michelow BJ. Giant congenital pigmented nevi of the face: Operative management and risk of malignancy. (In press)

35. Rhodes AR, Wood WC, Sober AJ, Mihm MC Jr. Nonepidermal origin of malignant melanoma associated with a giant congenital nevocellular nevus. Plast Reconstr Surg 1981;67:782-90. 
36. Keall J, McElwain TJ, Wallace AF. Malignant melanoma in childhood. Br J Plast Surg 1981;34:340-1.

37. Rhodes AR. Pigmented birth marks and precursor melanocytic lesions of cutaneous melanoma identifiable in childhood. Pediatr Clin North Am 1983;30:435-63. 